\title{
BMJ Open Experiences of how services supporting women with perinatal mental health difficulties work with their families: a qualitative study in England
}

\author{
Billie Lever Taylor, ${ }^{\oplus 1}$ Jo Billings, ${ }^{1}$ Nicola Morant, ${ }^{1}$ Debra Bick, ${ }^{2}$ Sonia Johnson ${ }^{\odot}$
}

To cite: Lever Taylor B, Billings J, Morant N, et al. Experiences of how services supporting women with perinatal mental health difficulties work with their families: a qualitative study in England. BMJ Open 2019;9:e030208. doi:10.1136/ bmjopen-2019-030208

- Prepublication history and additional material for this paper are available online. To view these files, please visit the journal online (http://dx.doi org/10.1136/bmjopen-2019030208).

Received 5 March 2019 Revised 20 June 2019 Accepted 21 June 2019

Check for updates

(C) Author(s) (or their employer(s)) 2019. Re-use permitted under CC BY-NC. No commercial re-use. See rights and permissions. Published by BMJ.

${ }^{1}$ Division of Psychiatry, University College London, London, UK

${ }^{2}$ Warwick Clinical Trials Unit, Warwick Medical School, University of Warwick, Gibbet Hill, UK

Correspondence to

Dr Billie Lever Taylor;

billie.taylor@ucl.ac.uk

\section{ABSTRACT}

Objectives Partners and wider family members play a vital role in relation to women's perinatal mental health. Clinical guidelines in the UK and internationally recommend that services supporting women with perinata mental health difficulties involve and support their families too. However, little is known about family members' needs and experiences, or whether they feel included by mental health services. This study set out to explore this. Methods This research formed part of a wider study exploring experiences of perinatal mental health care in England. The broader study included semi-structured interviews with 52 women across England who received treatment for a perinatal mental health difficulty, and 32 family members identified by the women as offering them some support. Data from these 84 interviews relating to how services work with partners and families were extracted and analysed thematically.

Results Analysis identified three overarching themes: (1) the centrality of women's families to their perinatal mental health/access to support, (2) experiences of partners and families being excluded by services and (3) ambivalence among women and their families about increasing family involvement/support. We found that partners and families appear to have an important influence on women's perinatal mental health, access to care and interactions with services, but that services tend to focus on individual women (and babies) with little regard for their wider family context. The complexity of involving and supporting partners and families, coupled with anxiety about this among women and their families, reinforces the tendency to marginalise them.

Conclusion Involving women's families and providing the support they need is challenging, but important. Experiences of women and their families of services treating perinatal mental health difficulties suggests greater focus is needed on overcoming barriers to family inclusion and on challenging underlying gender roles and expectations, rather than allowing these to shape and guide practice.

\section{INTRODUCTION}

Mental health difficulties in the perinatal period (defined as pregnancy and the first year post-birth) are prevalent, affecting women as well as their partners and wider

\section{Strengths and limitations of this study}

- This study addressed a gap in the research literature, by interviewing women, their partners and members of their wider family about their experiences of how services supporting women with perinatal mental health difficulties work with families.

- There is increasing policy emphasis on the need for mental health services to include and support families of perinatal women, but relatively little is known about how this is experienced in practice.

- This study included a large, diverse group of perinatal women and their family members with experience of a wide variety of mental health services, including mother and baby units, acute psychiatric wards, specialist perinatal community teams and generic non-perinatal community teams.

- To our knowledge, this is the first published study to explore experiences of perinatal mental health care among wider family members as well as women's partners.

It would have been useful to have explored clinician views of family involvement as well.

families, as families adjust to caring for a new baby. Research has shown that women's partners very often feel overwhelmed, lonely and frustrated when a woman experiences a perinatal mental health problem. ${ }^{12}$ Partners of women admitted to hospital with severe perinatal mental health difficulties report experiencing trauma, stress, fear, work-related difficulties and relationship problems. ${ }^{3} 4$ Almost one in five marriages ends following an episode of postpartum psychosis ${ }^{5}$ and maternal postpartum depression is associated with paternal postpartum depression. ${ }^{6}$ While very little research has focused on women's extended families, one study found that - along with partners - siblings, parents and grandparents of women experiencing postnatal depression said the difficulties resulted in 'a lot of worry within the family'. 
Research suggests there can be adverse outcomes for children too. ${ }^{8}$

Partners and other family members also play a vital role in relation to women's perinatal mental health. Greater perceived support from a woman's partner or own mother is significantly correlated with lower rates of postnatal depression among first-time mothers, ${ }^{9}$ while having a supportive partner is strongly associated with shorter hospital stays among women with severe perinatal mental health difficulties. ${ }^{10}$ New mothers are also more likely to turn to their partners for support with their difficulties than to anyone else, ${ }^{11}$ while some are reluctant to access help because their partners dismiss their symptoms. ${ }^{12}$

Best practice guidelines for perinatal mental health in the UK and internationally recommend including women's families in their care and supporting family members as well. ${ }^{13} 14$ Nevertheless, our recent systematic review and meta-synthesis found that, across a range of countries, partners of women with perinatal mental health difficulties reported feeling marginalised by services and confronted by a largely mother-baby-oriented environment. ${ }^{15}$ Our meta-synthesis also identified ambivalence on the part of women's partners about seeking greater support and involvement. These findings appeared to be connected to wider social trends: it has been argued that, although fathers increasingly aspire to be more 'involved' in the perinatal period and beyond, societal pressures and norms continue to relegate them to the periphery, while persisting beliefs about masculinity and fatherhood discourage them from seeking support for themselves. ${ }^{16}$ Meanwhile, women are seen as 'natural' nurturers, with emphasis placed on the importance of the mother-infant relationship, and with mothers viewed as holding primary responsibility for the emotional health of the infant. ${ }^{17}$

Despite these insights, the studies identified by the systematic review had important limitations. In particular, many only touched briefly on partners' experiences of services, as part of a wider remit, and it was not always clear to which services or professionals the findings referred. Additionally, no studies were found that investigated views of services among family members other than partners. Given the increasing recognition that services treating perinatal mental health difficulties need to 'think family', ${ }^{18}$ further research into partner and family experiences is needed and may provide useful insights for clinical practice.

The present study therefore sought to expand on previous research by exploring the role of partners and wider families in relation to women's perinatal mental health/access to services and experiences of family inclusion by services supporting women with perinatal mental health difficulties. Women's views were included along with those of their partners and wider families to allow different perspectives to be considered.

\section{Methods}

This study was part of a wider research programme exploring the effectiveness of services treating perinatal mental health difficulties. As part of this research programme qualitative, semi-structured interviews were conducted with 52 women who had accessed National Health Service (NHS) treatment for a variety of perinatal mental health difficulties, and 32 of their partners/family members. These interviews explored participants' views and experiences of a wide range of mental health service(s). The current study focused on analysing those sections of the interviews relating specifically to experiences of how services worked with partners and families.

\section{Recruitment}

Women

Women were recruited from 11 NHS healthcare providers, across different areas of England, which varied in their urbanicity. Women were purposively sampled to obtain diversity of diagnosis, service use and sociodemographic background. Inclusion criteria required that women were 16 years or over, English language speakers, had accessed NHS treatment for a perinatal mental health difficulty (during or after their most recent pregnancy) and had a baby aged 6 to 9 months old. Eligible women were identified and approached by a clinician within their mental health team. Those expressing an interest in participating were contacted by a researcher to provide them with more information about the study and obtain informed written consent if they were willing to take part. It was not possible to determine how many women refused participation as researchers were only informed of those who were interested.

\section{Family members}

As previously stated, for each participating woman, a partner or other family member was also interviewed wherever possible. Women were asked if they were able/ willing to identify a family member, with some involvement in supporting them, and ask them if they might be willing to take part too (although women could still participate even if no one from their family could be interviewed). A researcher got in touch with family members who were potentially willing, to provide them with more information about the study. Informed written consent was obtained from all participating family members. Inclusion criteria required that participating family members were: 16 years or over, English language speakers and were the partner/family member of a participating woman with some involvement in supporting her.

\section{Data collection}

Interviews took place between June 2015 and March 2017, usually in participants' homes. Participants were asked, in semi-structured interviews lasting around an hour in total, about their views and experiences of all the services women had accessed for their perinatal mental health. As outlined, the current study focuses specifically on the interview sections relating to partner/family involvement. Specifically, women were asked: Can you 
describe how services and professionals worked with other people who were supporting you and your baby (eg, your partner, baby's father, family members or friends)? Partners/family members were asked: What has been your role in supporting (mother) through this period? Can you describe how involved you have felt in (mother's) support and treatment? Can you describe any support you've received from services or professionals as someone supporting a mother who is having difficulties? Follow-up probes to these main questions were used as appropriate to encourage participants to give full accounts of their experiences. Given the qualitative nature of the study, related issues were sometimes also touched on elsewhere in their interviews and were included in the analysis where relevant. Participants were informed that their contributions would be kept confidential with identifying details removed, but that the researcher would pass on information if he/she had major concerns about their safety or that of others; ultimately concerns were passed to social services in relation to information provided by one woman (with her agreement).

Interviews with women were carried out separately to family members, with a few exceptions. Most interviews $(\mathrm{n}=70)$ were conducted by the first author, who is a clinical psychologist, researcher and mother. A small number $(n=14)$ were also carried out by: a professor of social work, a member of the study's perinatal service user and carer advisory group and two Master of Science students studying clinical mental health sciences.

\section{Analysis}

Interviews were audio-recorded, transcribed and anonymised. Researcher notes were also written up after each interview. In two cases, interviews were accidentally not recorded and researcher notes were analysed instead. Thematic analysis was used, ${ }^{19}$ with themes and subthemes identified in a cyclical process of reading, coding and exploring patterns in the data. To enhance validity, a second researcher independently coded nine interviews with women and seven with family members, with consensus reached on the coding frame through discussion.

Analysis was facilitated by using NVivo qualitative analysis software. Given the large number of interviews, two separate data sets were created; one for women and one for family members. Participants in each data set were also categorised by the type(s) of service women accessed. Contrasts were explored across participant groups and services: several key themes were universally reported across different groups but findings unique to types of participant (eg, male partners) or service (eg, mother and baby units (MBUs)) were also identified.

\section{Patient and public involvement}

Interview guides were developed by the research team and reviewed and amended by a perinatal service user and carer advisory group (with experience of perinatal mental health care). Pilot interviews were carried out with one woman and one partner from this group, and then with four other women who had accessed perinatal mental health support, and two of their partners/relatives. The latter six interviews were included in the final sample since they met study eligibility criteria and only minor changes to the interview schedules were needed (eg, to reduce the number of probes and expand the opening/introductory text). Five of the main study interviews were then carried out by a woman from the advisory group, and another woman from this group, along with two partners, also reviewed the manuscript which was edited based on their feedback.

\section{RESULTS \\ Characteristics of participants and services accessed}

Tables 1 and 2 show participants' characteristics. Women had a range of diagnoses including depression, psychotic disorders, personality disorder and anxiety disorders. Their mean age was 32 years (range: 19 to 43) and around two-thirds were living with a partner.

Just over two-thirds of participating family members were women's partners (one female, the others male), while around a fifth were parents of participating women (referred to as 'grandparents'). The mean age of women's partners was 34 years (range: 23 to 48), while for grandparents it was 54 years (range: 39 to 67) (the young age of grandparents may reflect the fact that they were often the chosen source of support for the younger and single mothers included).

The mental health services which women had accessed, and on which participants thus based their experiences, were diverse. Details of the main services participants described are given in table 3 . Some women (with a range of diagnoses) were admitted with their babies to specialist MBUs, while others were separated from their babies, as they were admitted to general psychiatric wards with no provision for infant care. In the community, some women were treated by specialist secondary care perinatal mental health services (for a range of moderate-to-severe difficulties), or by specially trained mental health midwives or health visitors (for milder difficulties). Others received support from generic, non-perinatal mental health services such as crisis teams (for acute difficulties), multi-disciplinary community mental health teams (for moderate-to-severe difficulties) or services offering talking therapies, usually cognitive-behavioural based (for milder difficulties). Some women also received support from non-perinatal services specialising in particular diagnoses (eg, early intervention in psychosis services). Many women accessed more than one service.

\section{Overview of themes}

Three overarching themes were identified in the analysis: (1) the centrality of women's families to their perinatal mental health and access to support, (2) experiences of partners and families being excluded by services and 3) ambivalence among women and family members about increasing family involvement/support. Table 4 shows 
Table 1 Key characteristics of participating women $(n=52)$

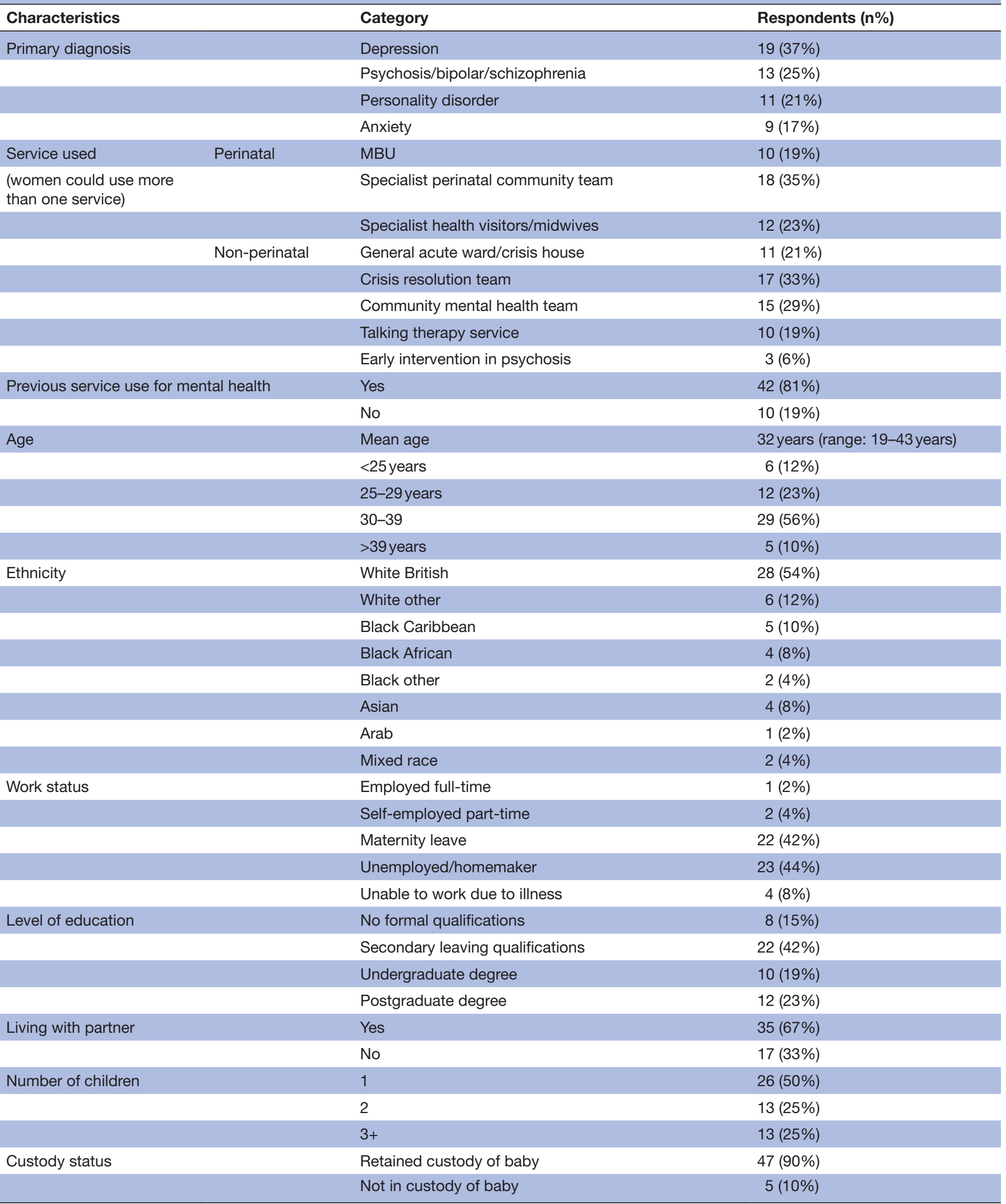

MBU, mother and baby unit.

subthemes for these, each of which is presented and elaborated on in the text below. Given the large and diverse samples included in this study, online supplementary file
1 and 2 provide an overview of how participants' views and experiences vary in relation to different types of mental health services (online supplementary file 1), and 
Table 2 Key characteristics of participating family members $(n=32)$

\begin{tabular}{|c|c|c|}
\hline Characteristics & Category & Respondents (n\%) \\
\hline \multirow[t]{3}{*}{ Relationship to mother } & Husband/partner & 22 (69\%) \\
\hline & Mother/father ('grandparent') & $7(22 \%)$ \\
\hline & Other relative (eg, sister/child) & $3(9 \%)$ \\
\hline \multirow[t]{7}{*}{ Age } & Mean age (partners) & 34 years (range: $23-48$ years) \\
\hline & Mean age (grandparents) & 54 years (range: $39-67$ years) \\
\hline & Mean age (other relatives) & 21 years (range: $17-24$ years) \\
\hline & $<25$ years & $4(13 \%)$ \\
\hline & 25-29years & $8(25 \%)$ \\
\hline & $30-39$ & $10(31 \%)$ \\
\hline & $>39$ years & $10(31 \%)$ \\
\hline \multirow[t]{5}{*}{ Ethnicity } & White British & $19(59 \%)$ \\
\hline & White other & $6(19 \%)$ \\
\hline & Black Caribbean & $2(6 \%)$ \\
\hline & Black African & $2(6 \%)$ \\
\hline & Asian & $3(9 \%)$ \\
\hline \multirow[t]{2}{*}{ Living with mother } & Yes & $26(81 \%)$ \\
\hline & No & $6(19 \%)$ \\
\hline \multirow[t]{6}{*}{ Work status } & Employed full-time & $15(47 \%)$ \\
\hline & Employed part-time & $1(3 \%)$ \\
\hline & Self-employed full-time & $4(13 \%)$ \\
\hline & Self-employed part-time & $1(3 \%)$ \\
\hline & Student & $3(9 \%)$ \\
\hline & Unemployed/retired/carer & $8(25 \%)$ \\
\hline \multirow[t]{5}{*}{ Level of education } & No formal qualifications & $1(3 \%)$ \\
\hline & Secondary leaving qualifications & $19(59 \%)$ \\
\hline & Undergraduate degree & $6(19 \%)$ \\
\hline & Postgraduate degree & $5(16 \%)$ \\
\hline & Not recorded & $1(3 \%)$ \\
\hline
\end{tabular}

in relation to their status as direct service users (women with perinatal mental health difficulties), partners or wider family members (online supplementary file 2). Overall, women, their partners and wider family members considered that families were marginalised by services and should be better included and supported. But they also described some unique anxieties about this. While all types of mental health service were reported to marginalise families, MBUs were seen as the most inclusive.

\section{The centrality of the family to perinatal mental health and access to support}

A key finding expressed by women, partners and other family members centred on the importance of women's families to their difficulties, interactions with services, and longer-term recovery. This view was expressed irrespective of diagnosis, with findings indicating that a woman's mental health needs should be addressed with reference to her family and interpersonal context.

\section{The role of interpersonal transition and conflict}

Women and their family members described pregnancy and having a baby as a major life transition: it resulted in shifts in their roles, relationships and identities, and this could provoke distress. Though the adjustment could be particularly marked for first-time parents, the addition of further children could also disrupt the status quo.

It was conspicuous how frequently participants linked interpersonal conflict and tension to the woman's difficulties. Women, in particular, often cited discord with their partner or wider family as contributing to, or exacerbating their mental health difficulties. Several described their relationships with partners, as well as with wider family members and friends as having broken down during pregnancy or after giving birth, often leaving them struggling to live up to their image of the 'perfect' mother, and to cope with their babies singlehandedly. Other women felt frustrated and overburdened, saying their partners did not help enough with 
Table 3 Description of key services included

\section{Specialist perinatal or non-perinatal service} Type of service

\section{Brief description}

$\begin{array}{ll}\text { Specialist perinatal } \quad \text { MBU } & \text { Specialist hospital } \\ & \text { where women with } \\ & \text { acute mental health } \\ & \text { difficulties are admitted } \\ & \text { together with their } \\ & \text { babies }\end{array}$

Specialist perinatal Multidisciplinary teams community mental treating women in health team

the community with moderate-to-severe perinatal mental health difficulties

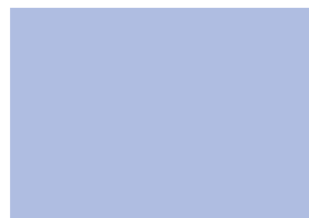

\section{Specialist health Health visitors} visitors/midwives and midwives with additional training to offer support to women with mental health difficulties

Non-perinatal

General acute psychiatric ward

General psychiatric hospitals for adults with mental health difficulties where women can be admitted (without their babies)

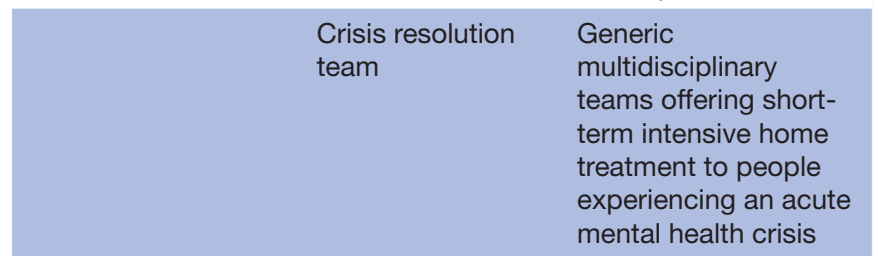

Early intervention in Multidisciplinary teams psychosis service offering long-term, intensive support to people experiencing a first episode of psychosis

\begin{tabular}{lll}
$\begin{array}{l}\text { Community mental } \\
\text { health team }\end{array}$ & $\begin{array}{l}\text { Generic } \\
\text { multidisciplinary } \\
\text { teams treating adults } \\
\text { with moderate-to- } \\
\text { severe mental health } \\
\text { difficulties }\end{array}$ \\
& $\begin{array}{l}\text { Generic community } \\
\text { Talking therapy } \\
\text { services }\end{array}$ & $\begin{array}{l}\text { servies psychological } \\
\text { therapy for anxiety and } \\
\text { depression }\end{array}$ \\
\hline
\end{tabular}

MBU, mother and baby unit.

the new baby, or did not really understand how difficult motherhood was.

When I first told (my husband) about my depression... he just didn't get it. And it's almost like anything I say is an attack on him...or 'Oh, well, if you're feeling depressed, imagine how I'm feeling, you know, trying to work and pay the rent'...And he's self-employed, so if I do want to go out or something...he's
Table 4 Themes and subthemes identified

Themes Subthemes

Centrality of women's families The role of interpersonal to their perinatal mental transition and conflict health and access to support

Influence of the family on support and recovery

Experiences of partners and Overlooking families families being excluded by services

Lack of support for partners and other family members

Difficulties balancing
women's and family
members' needs

Services ill-equipped for complexity of family involvement

Structure of services and separation of families

Ambivalence about increasing Feared consequences of family involvement/support family inclusion/support

Partners and other family
members have to 'stay
strong'

like, 'I can't be turning work down.'...I've not gone out in the evenings since having the baby... He said, 'Oh, we've had so many problems since the baby was born'...She's nearly torn us apart. (Mother 37)

Some participants, most commonly women's partners, expressed the view that family relations had become strained as a result of the woman's mental health difficulties, rather than vice-versa - for example saying they believed women became difficult, or even suspicious and hostile towards their families, because of postnatal depression or psychotic delusions. In some cases, women's partners also felt rejected or deprioritised by them after the birth of the baby, prompting clashes and distress.

I've had my own challenges as well with the change in our lives...If I was on (my wife's) list before, I'm- I was at the bottom of the list, I'm now not on the list...

You don't have an adult relationship in the same way that you did...You know, I come in from work and (my wife) wants to get to bed early if she's tired. So you have those sort of like clashes really. (Partner 4)

These turbulent relationship shifts were not confined only to women and their partners. Sometimes grandparents or, less frequently, other relatives were also heavily involved (eg, where women's relationships with their partners had broken down) and, in such cases, the birth of a baby often necessitated a reorganisation of wider family relations too. For example, one single mother was living with her father and he associated her difficulties 
partly with their own shifting relationship in the context of a new baby.

I know that at the moment (my daughter's) suffering with a bit of postnatal depression...I know because she has screaming rows...

When we argue about stuff, the crux of the argument, when we're sort of nose to nose is, 'I'm not your ****** boyfriend and I'm not his dad. You don't get to-, if I was his dad you could talk to me like that...But I'm not, I'm your dad.' And from (my daughter's) point of view it's like, 'I'm raising this baby on my own'...That kicks me right in the teeth because it's like, 'I'm here.' (Grandparent 3)

Overall, although it was the women who had been given the diagnosis of a perinatal mental health problem, their difficulties were frequently embedded within a complex and fraught wider interpersonal context, where the whole family was struggling.

\section{Influence of the family on support and recovery}

Women's contact with mental health services took place in the context of the complex, shifting family dynamics described. It was clear that family circumstances, and the attitudes and behaviours of family members, influenced women's access to support, interactions with services, and recovery. Women who had some of the 'worst' outcomes (eg, the five women who had lost custody of their babies) were typically living in particularly challenging family contexts, categorised by conflict, relationship breakdown and sometimes violence and abuse from partners or other family members. When women perceived their families to be unsupportive or dismissive of their struggles, it could increase or prolong their distress.

(My husband) was like...'You're not the woman I thought you were. This behaviour is just awful. You're not loving the children.' And it just wasn't working. And then eventually it got worse. I think I, within 2 weeks anyway I was like completely suicidal. (Mother 11)

In a few cases, partners or other family members put pressure on women not to access support. This could be because they were anxious about women taking medication, or feared professionals might judge the family negatively, or even take the baby away. In some cases, women turned down treatment because of perceived family resistance; in other cases they kept their treatment secret. This could be especially sensitive for women from ethnic minority backgrounds, who sometimes reported that perceived stigma around mental health within their wider family and social networks resulted in them hiding their difficulties and treatment from their families.

On the other hand, there were numerous instances where partners and other family members were supportive of women's treatment and recovery. They were often seen (by women in particular) as instrumental in identifying women's difficulties, encouraging them to get help and assisting their recovery, with some family members describing their relief when women accessed support. Women with proactive family members supporting and advocating for them seemed to get access to professional support more readily than those without.

Furthermore, when women struggled, their partners and wider families frequently took over household chores or helped more with the baby, for example doing night feeds or looking after the baby while the woman attended appointments or was hospitalised. Women from some cultural backgrounds (eg, Asian) sometimes reported that a high level of involvement with infant care from extended family networks was the norm. For other families, taking on extra responsibilities could put a strain on partners and wider families as well and, in some cases, they also blamed themselves for what had happened.

As a man, or partner, husband, you feel like it's your fault your partner is the way that they are...Maybe I've not loved her enough. Maybe I've not helped enough. But really, in essence, you're probably doing as much as you can, or doing more than what you normally do...I blamed myself a little bit, not just for, you know, the pregnancy and the baby, but just, I don't know, everything really. (Partner 15)

\section{Experiences of partners and wider families being excluded by services}

Despite their perceived importance, many of those interviewed believed families were excluded by services supporting women with perinatal mental health difficulties. Experiences of this were reported by women, partners and wider family members across different demographics, diagnoses and service types, although MBUs appeared to be more inclusive of families than other services. Analysis suggested that this exclusion of families was manifested in various ways including: not being invited to or included in appointments; not being provided with information about, or helped to understand, the woman's mental health problems; not being involved in treatment decisions; their own distress and difficulties not being acknowledged and not being offered any support for these difficulties.

\section{Overlooking families}

It was common for women and their family members to say that professionals overlooked partners and wider families, focusing their attention exclusively on women and their babies. Mirroring this, some participants conceded that they too had given little thought to family involvement - for example, not thinking to ask if family members could attend appointments/access support themselves even if, in hindsight, women and their family members alike thought this could have been valuable.

Within community mental health services in particular (both specialist perinatal services and generic, non-perinatal services) there were sometimes few opportunities for family members to become involved or meet clinicians 
(eg, where they weren't invited to appointments), and a sense that there was no real 'place for, like, a husband' (Partner 15). As a result, women's families often felt poorly informed about their difficulties and treatment; they were unsure exactly what support a woman was receiving, what to expect and how best to help her.

I wing it every day with supporting (my partner), so I don't know the correct way... There's been no support there to help me. I feel sometimes the best way for me to support (her) is just agree with her and deal with it after...But I don't know whether that's the right way to go about it overall. She's got a (specialist perinatal) psychiatrist. What about support for the dad in this case? (Partner 14)

A number of women and their family members wanted families to be included in at least some appointments; they felt this would both allow them to contribute their own observations, and also help them better understand and support women.

It would've been nice to have had a bit more involvement (with the talking therapy) as far as, you know, meetings or otherwise just so that I have a better grasp to understand what issues we're dealing with...I guess I didn't know, within the structure of how everything works, how I could get involved.(Partner 5)

(My husband) wanted to speak to professionals to tell them his side...I would (have liked that too), just to see, you know, because he's not like the easiest of men, but then he's not responded in a way that I needed him to respond...And he's never ever approached me in a way he needs to approach me, so it makes me worse. (Mother 50)

When mental health professionals visited women at home, family members really valued being included and asked for their input. But some felt they were ignored.

I've never really talked to (the early intervention service care coordinator)...Like she comes here and talks to (my wife). Doesn't really say much to me or doesn't ask me, 'How do you think she is?', or things like that. I mean nothing...It would have been nice for her to say, 'Well I'll involve you in some of the meetings.' But you don't get nothing. (Partner 11)

Where women were admitted to MBUs or psychiatric wards, their families were more likely to have at least some contact with clinicians on inpatient units. For example, they might speak to them when visiting women or arranging visits, and some were involved in treatment decisions if women were judged to lack capacity. MBUs were praised overall for working collaboratively with women's families, regularly communicating with them, as well as inviting them to be present at ward rounds and taking their views into account. By contrast, family members had to be proactive and persistent to get staff on general psychiatric wards to keep them updated on the woman's condition and treatment plan. A few women said staff on acute wards treated them like 'a single person' (mother 44), hardly acknowledging their families, and sometimes not even realising they had a new baby. One man, whose partner stayed on both an MBU and an acute ward, described the MBU as more inclusive of him than the acute ward.

Two or three days go and then I would call (the ward) again because they never, well they hardly ever called me. It was me trying to find out things all the time.

I was asked to attend (meetings at the MBU) if I wanted to. You know, they wanted me to attend to see...It was run like with partners in mind. They wanted the partners to be involved and to, you know, to help in the whole process. (Partner 20)

\section{Lack of support for partners and other family members}

As well as wanting information about and involvement in women's support, some partners and family members said they would have valued emotional support from mental health professionals themselves, for their own distress; they wanted help coping with the effects of the woman's mental health problems on them, and addressing their own difficulties adjusting to life with a new baby. Across our data corpus and regardless of community, inpatient, perinatal or non-perinatal mental health settings, few accounts were provided of support targeted at family members.

In general, families wanted support to be offered faceto-face or over the telephone: 'It would have been nice if somebody was there to just call me occasionally saying, 'How are you doing?" (Grandparent 6). In particular, they wanted professionals to acknowledge how difficult things were for them and check how they were doing. Several partners and other family members felt that nobody was thinking about them.

I felt I wasn't being more involved, like, and no one's coming to me, like, 'How are you doing? How is your mental health state?' And all this, you know. Because it's not easy. And I get a bit, like, okay. No one's asking me how I am. How about me? I thought, it's not only her going through this, it's me. I'm there and all. (Partner 7)

There were a few exceptions where professionals, most commonly perinatal specialists on MBUs or in the community, had acknowledged family members' needs and engaged with them too, and when this happened it was valued.

(I had) lots of, just informal chats...Different members of the (MBU) staff would ask me how I'm coping, am I all right? How are things at home? And sometimes I sort of took up the offer to sit and have a bit more of a chat. (Partner 12)

However, even when support had been offered, it was frequently viewed as superficial, insufficient or too late. 
I was offered support (after my wife's MBU admission), but it was all sort of quite late on in the process. And kind of, ultimately, you had a meeting with someone at home. They were very nice. But none of the things that were due to be followed up on were followed up on. (Partner 17)

\section{Difficulties balancing the needs of women and their family members}

In some cases, rather than simply overlooking partners and wider families, respondents' accounts suggested that clinicians may have excluded partners or family members because of concerns that involving them could reduce the focus on the needs of the woman (and baby), or because they were mindful of the need to protect women's potential desire for confidentiality from their families. These issues were complex; as outlined, some women kept aspects of their mental health or treatment secret from their families, while others described experiencing turbulent, unequal and sometimes coercive and abusive relationships, meaning privacy and time alone with professionals could be vital. Prioritising the needs of women and babies, and keeping a clear focus on them, seemed essential in this context. Yet it could also leave family members feeling shut out. Several family members, across different types of service, described how they had wanted to put across their own opinions (eg, if they felt a woman was struggling more than she admitted, or wanted to tell professionals that a woman's hostility towards them was, in their view, really driven by paranoia, psychosis or similar). But they felt mental health professionals were unwilling to speak to them or appeared cautious or mistrustful of them (occasionally also linking this to the female-dominated nature of staff within both perinatal and non-perinatal mental health services).

I wanted to say to the (specialist) health visitor, 'Look maybe do you think that this could be postnatal depression...?' I would have liked the chance to discuss it with her. Not that I wanted to encroach on any of (my daughter's) time with her...But alas...If I was in the room then everything sort of stopped until I left the room, and then they recommenced...The minute I walked in it was like tumbleweed. (Grandparent 3)

For their part, some women who desired privacy from their families had still wanted them involved in some way. For example, one woman from an ethnic minority background saw value in involving her husband in her care, but at the same time kept some details of her difficulties secret from him due to perceived cultural stigma around mental health. She wished professionals had helped her negotiate this, offering her more options for how he might be included given this context.

(The community mental health team) haven't told me, 'How would you like us to involve (your husband)?' They just told me to bring him to my appointments. But I don't want to bring him to my appointments because they might bring up something that he doesn't know and then that would just cause problems afterwards... (I'd like to) take him along with me (so he could get) some sort of understanding...But like I said, it's either come to my appointments or don't get involved. (Mother 35)

However, adding to the complexity, a few participants said that too much emphasis on involving partners or family members could leave women themselves marginalised. This suggested that professionals at times experienced difficulties determining the appropriate emphasis to place on different people's needs or perspectives - especially where interpersonal relationships were strained.

When you're in hospital, they hardly listen to you. Well, this is my experience, my feeling. That, it's like they hardly listen to you at all because they know the reason you're in hospital is because you're unwell. So they listen to (my husband). (Mother 26)

Nevertheless, there were a small number of examples that suggested it was possible to protect women's needs without excluding their families, even in difficult circumstances. These were usually cases where professionals had built up a good picture of the family context, for example in non-perinatal mental health teams which had been involved longer-term, not only during the perinatal period. For example, the partner of one woman (who had a pre-existing diagnosis of bipolar disorder and experienced postpartum psychosis) described how, although he initially felt marginalised by community mental health team clinicians, he felt they had got to know the family situation better over time, and became more adept at meeting both his and his wife's needs.

It's been a very fine line to tread for them and they've done it very well... Not making me feel excluded... Not using confidentiality as a rather convenient way of just not having to deal with me...But finding sensitive and appropriate you know, professionally appropriate ways around that so that they get the information they need from me...And that I still feel supported. (Partner 12)

\section{Services ill-equipped for complexity of family inclusion}

As the findings above suggest, complex interpersonal dynamics between women and their families meant family involvement was not always straightforward. There were indications that mental health professionals at times felt ill-equipped or under-resourced to deal with this complexity, marginalising family members as a result. For example, in one case, a woman believed her perinatal nurse excluded her partner from appointments because she did not feel suitably trained to deal with the tensions in their relationship. Nobody else, she said, was able to support her partner or see them together either. 
I'm just, basically like, surprised that there is no support system for carers, or friends, or partners, or family members, there's no support system whatsoever...

(My perinatal mental health nurse) doesn't want to make it worse. It's like a very different, couples therapy, like dealing with two people in the same room who've got conflict with each other, it's a very different thing, yes. And like, so I think, I don't know how many years of training it is, but like, she doesn't have that training, she can't do it, yes. (Mother 8)

There were a few exceptions, where participants described practitioners, most often specialist perinatal practitioners, as engaging confidently with the family context; this was appreciated. Yet in other cases, partners and family members believed professionals excluded them because their perspectives could be awkward or difficult.

I'm quite happy to go in there and say to them, 'I don't like the way you're doing this' or, 'I don't think it's right what you're doing' or, 'you shouldn't be doing it.' And I don't think they liked it...And I just think it's because, a bit of bad blood between us that they just distanced their self away. (Grandparent 5)

Where wider families were involved, in particular when grandparents were helping single mothers, they sometimes also felt that professionals were ill-equipped to consider their unique role and needs. Likewise, in unconventional family set-ups, family members could feel poorly accommodated, for example where women had new partners who weren't the baby's biological father.

It's a grandad's role...You're looked at from the outside world, from doctors and health professionals and psychiatric healthcare professionals as a dad in that situation...Because the dynamic of families has changed, the dynamic of the help that is offered to them should be changed. (Grandparent 3)

\section{The structure of services and separation of families}

Finally, broader structural issues were sometimes referred to in relation to how and why partners and families were marginalised from services. In particular, participants noted that inpatient admissions involved separating family members from each other, often meaning that partners or relatives cared for babies (or older children) single-handedly while women were hospitalised. While women and their families generally preferred specialist MBU admissions with their babies over acute ward admissions without them, a disadvantage was that family members were separated not only from women but also from babies. Although MBUs were perceived as collaborating better with women's families than other services, some family members felt their set-up made it difficult for families to fit in, and that the consequences for them of the separation were not fully acknowledged.
The only thing that could have been improved on from my perspective was a bit more recognition from the, the nursery nurses...I'm not resident (on the MBU), I haven't got my stuff there. It's, it can be quite tricky to suddenly slot into your father role... Not having had a chance to get to know your baby very much. (Partner 12)

A scarcity of MBUs nationwide, and the wide areas they served, also meant women were regularly admitted to facilities far from home, meaning their families often faced long journeys to visit them, with little or no financial support for travel. Nonetheless, MBUs were seen as accommodating family visits well. This contrasted with acute wards, where experiences of visiting were less positive.

You can hear shouting, you can hear screaming...It would be nice to have had a family room away from the ward...You want to take your child for a walk in the gardens...No. You had to be stuck in that room. Like I say, it felt like a prison. (Partner 21)

Family members also wanted more support from both MBUs and acute wards post-discharge, to help them readjust to life back at home with a new baby and to cope with any ongoing difficulties. Some felt that a lack of focus on women's wider family contexts meant women were sent home to the same turbulent dynamics in which their difficulties first arose, resulting in them struggling again.

Everything was just put in place with (my daughter). So there was no following up for me...But if I got the support...how to help (my daughter)...you know, how to hold her little family together, I think that would've been so much better. If (the MBU) did something with the parents or grandparents... because she was coming right back home...so if the support is not there for her...We didn't hope that (she) would go back in hospital again, but it happened. (Grandparent 2)

In community settings, structural factors could also contribute to marginalising families. This could occur when women were seen individually in clinics rather than in their home environment, when family members were invited to appointments but could not attend because they were during working hours, or where support for family members was offered at inconvenient times and in awkward locations.

They're telling me I have to take time off during the week to get the support we need but I'm saying, 'Why don't you work a weekend so we can get the support that we need?' (Partner 14)

Across all service types there were indications that participants wanted services to be structured in a way that was more family-oriented or holistic. In inpatient settings, some participants wished family members could stay overnight on MBUs, with a few women refusing admission 
because they did not want their family separated. In the community, some women (and, less commonly, partners) wanted couples/family therapy, saying their difficulties had persisted after treatment, and that they saw addressing the interpersonal context as important to resolving their struggles. There were also examples of women questioning why they were treated and medicated for what they saw as interpersonal difficulties.

It would've been nicer to have sort of a more family, I know it doesn't really exist, but more of a family place that you could, so your partner and mother, so father, mother and baby could all go there. And there'd be support for everybody...I think a lot of people would benefit from it. (Partner 21)

\section{Ambivalence about family involvement and support}

Despite ostensibly wanting more family inclusion and support, many participants simultaneously seemed unsure about this, suggesting underlying ambivalence. This was not indifference on their part, but rather appeared to relate to anxieties about what greater family involvement or support would mean, whether it might make unmanageable demands on them, or have other undesirable consequences. Women's and their partners' and relatives' mixed feelings about family involvement sometimes seemed to reinforce the tendency for services to marginalise families creating a vicious cycle.

\section{Feared consequences of family inclusion/support}

Women's partners and other family members often described struggling with the burden on them. Many were trying to hold down a job, as well as to support the mothers and cope with the challenges of a new baby. Although they felt neglected by services, the idea of greater involvement, let alone taking up support themselves, could also feel unmanageable, given the competing demands on their time: 'Even the thought of going to see a counsellor for an hour was just like, well I just don't have time for it.' (Partner 2).

Not only this, some participants appeared resistant to a greater focus on families for fear this might further disrupt their relationships or the 'status quo'. For example, in one case a woman believed her partner was reluctant to be more involved in her support or accept support himself for fear it might require him to face up to problems in their relationship, and change his behaviour and attitude towards her and their baby. Faced with his resistance, she said professionals seemed to back off, rather than persisting in exploring ways to engage with him.

I don't think (professionals) tried to help him enough to some degree. But then...he wasn't willing to work with me and (our baby)...He didn't want to work with them in any way, shape or form. And too much of self-centred and selfish person. He doesn't want to change... They haven't really tried to guide him in more taking it. They've left it more for him to do. (Mother 33)
It was also common for women themselves to express anxiety about the idea of family members being involved in their support, saying they would not 'understand'. This too appeared to relate in part to underlying concerns about what their involvement might mean for family relationships and whether family members might judge women negatively. It also seemed connected to underlying anxieties for women about how family inclusion might affect their protected time with clinicians and autonomy over their treatment, especially for those living in fraught family contexts. As outlined above, privacy was important for some women and, when family members were very involved, this could occasionally leave women themselves feeling deprioritised.

\section{Partners and other family members have to 'stay strong'}

Even though they struggled when women were distressed, and with the demands of a new baby, partners and other family members were often uncertain about accepting support themselves. Although they spoke of loss of sleep, anxiety, depression, stress, increased alcohol use and work-related difficulties, some were adamant that they did not need or want support themselves. Others expressed the view that they had to 'stay strong' and not 'indulge' their own needs. A few felt more comfortable staying 'in the background' (Partner 1) and many seemed only really to find it acceptable for the mother (and baby) to get help.

I was looking after (our baby). I still hadn't recovered from the sleep...So I kind of just, I don't need anyone's help, I'm just going to do this...And then, you know, after I'd go and see her at the MBU, and then I would have my cry...because I was in it and it was happening I just thought I don't really need any help, because it was (my wife) that needed the help. (Partner 2)

Several women also subscribed to the view that their partners and wider families were 'strong' and not in need of support. This reduced their inclination to focus on their needs or push for support for them.

A number of male partners meanwhile explicitly or implicitly connected their hesitation accessing support (including peer support) to beliefs that it was shameful and unmanly for men to voice needs. Male partners appeared to place a high value on not being 'over-dramatic': they wanted to wait to see if things would resolve of their own accord, and to work things out by themselves. At times this seemed to be partly connected to uncertainty about what it was 'normal' to feel in the perinatal period. However, there was also a sense that feelings of neediness challenged men's sense of self-worth.

As a man, you don't really need support. You think you can do it on your own. You'll be fine. (Partner 15)

It was conspicuous that, even when partners and other family members did want help, they often found it 
difficult to pinpoint exactly what it was they wanted. Some implied that they were willing to accept support to help them support women, but were not comfortable with support focused more directly on themselves. Several participants implied that men, in particular, were more likely to take up support that addressed their own needs if it was offered in an 'informal' or 'incidental' way.

I kind of enjoy socialising but I don't like being pushed to meet other people, so yes. That's just guys though, more like you know, just they like to do it if it's natural but if it's organised you almost like sniff something, is that a trap? (Partner 8)

This desire for support to be 'casual' or 'understated' also reinforced the earlier points, where some family members said they did not so much want formal support, as greater recognition of the challenges they faced. They wanted to be noticed: for a professional to ask how they were, or to suggest having an 'informal chat'.

\section{DISCUSSION}

In the UK, the newly published NHS long-term plan ${ }^{20}$ emphasises the importance of mental health services working with and supporting the families of perinatal women. The importance of this is also increasingly recognised internationally, both in Western and non-Western societies. ${ }^{13}{ }^{21}$ Yet relatively little is known about experiences of family involvement and support in practice. This study explored views of how services supporting women with perinatal mental health difficulties work with their families, from the perspectives of women, their partners and wider families. Women in the study had accessed treatment from a wide array of UK services for a range of diagnoses. They came from a broad mixture of socio-demographic and cultural backgrounds, and lived in differing family set-ups. Along with their partners and family members, they gave rich, qualitative accounts of their experiences.

Overall, analysis suggested that women's perinatal mental health difficulties need to be considered with reference to their family and interpersonal contexts. Contact with services takes place in the midst of complex relationship dynamics, which are in a state of flux with the arrival of a new baby. Although it was the women who had been diagnosed with perinatal mental health difficulties, their struggles often seemed to signify difficulties between family members, as much as within individual mothers, and with all members of a family experiencing distress. The perinatal period is a critical risk time for relationship strain and even domestic violence,,$^{22}$ and women in particular often connected their perinatal mental health difficulties to familial struggles (eg, expressing frustration at having to take on the bulk of parenting), with families also playing a major role in relation to access to support and recovery.

Despite this, services were experienced as focusing on individual women (and babies), and not often engaging in a meaningful way with families or the interpersonal context. Services were seen as being structured in ways that tended to exclude family members, and professionals were experienced at times as ill-equipped and under-resourced to work with families. Family members were not regularly included in appointments, or kept informed about women's treatment, or asked for their own perspectives, and there was a lack of acknowledgement of their needs or support for them. Though there were exceptions, this meant partners and families were often left feeling marginalised, unheard and unsupported, while women and their families said difficulties sometimes persisted after treatment because of a lack of wider focus. This study builds on our previous research which similarly highlighted the marginalisation of women's partners across a range of countries and service settings. ${ }^{15}$ This study suggests this marginalisation extends beyond partners to members of the wider family too. It also echoes wider research, which shows that partners and wider families can feel excluded by mental health services outside of the perinatal period too. ${ }^{23}$ Although families felt neglected across all types of service, MBUs were generally reported to be better at engaging with families than other services.

Nevertheless, responses also suggested that it could be complex for professionals to balance family inclusion with the need to protect and prioritise women and their babies. This was especially true in light of women's fraught and sometimes abusive family contexts and, in some cases, their expressed desire for privacy from their families. Not only this, although women's families ostensibly wanted to be better included and supported, they also expressed ambivalence about this. In line with previous research, ${ }^{25}{ }^{26}$ perceived norms of masculinity and fatherhood meant that male partners/fathers found it hard to acknowledge their own needs. Likewise, other family members often believed they had to 'stay strong'. Greater involvement and support could also feel unmanageable, given how much families already had to cope with, and there were signs too that women and their families were fearful about the possible disruption to their relationships and the 'status quo' that a greater focus on families could entail. This appeared to reinforce the tendency for services to overlook and exclude families, which, in turn, arguably contributed to increasing their perception of their own needs as insignificant in a vicious cycle.

Viewed in their broader context, the findings suggest that mental health services supporting perinatal women tend to reflect and reinforce pervasive social norms and practices around motherhood, fatherhood and infant development. As described in the introduction, in wider society women are typically seen as natural nurturers who are expected to assume primary responsibility for infant development; fathers are encouraged to be 'equal' partners but, in reality, are relegated to the periphery. ${ }^{17}$ Our findings suggest that these culturally-embedded expectations place pressure on both women and their families which - along with other challenges 
- can contribute to provoking perinatal distress and can bring family members into conflict with each other. Yet instead of seeking to understand perinatal distress within its wider context - or indeed to challenge the structures and norms that may produce and maintain it - services appear focused on diagnosing and treating individual women, arguably even aiming to help them adjust to their expected role as primary nurturers, while marginalising fathers and wider families. In this way, rather than challenging dominant norms, services allow them to shape and guide practice. This is arguably further exacerbated by wider persisting cultural views of women as prone to 'hysteria' (itself derived from the Greek for 'uterus'), with men expected to be emotionally undemanding, ${ }^{27}$ and by a broader tendency within psychiatry to see distress as located within individuals' minds, deflecting from the need to address people's wider social, political or interpersonal contexts. ${ }^{28}$

\section{Strengths and limitations}

This study addressed a gap in the research literature, by interviewing a diverse group of women, as well as their partners, and wider family members about experiences of how services work with the families of women diagnosed with perinatal mental health difficulties. Nevertheless, it also had several limitations.

First, as this study was nested within a wider research programme, only parts of each interview focused on experiences of family inclusion, limiting the time that could be spent discussing this topic, particularly as such a wide array of services were included. While rich data were nevertheless obtained, future research may benefit from dedicating full interviews to this topic. Second, interviews with women and their family members were analysed separately for the purposes of this paper. However, future research may benefit from analysing 'pairs' of interviews together to allow closer comparison and contrast of different perspectives. Third, while in most cases interviews were carried out separately with women and their family members, in exceptional cases both were present. This could have had implications for what participants were willing to share in these cases (eg, if they were unwilling to disclose some information in front of each other). Fourth, interviews were carried out at 6 to 9 months postnatally, when treatment was often very recent or ongoing. It may be valuable for future research to follow-up families later once they have had longer to reflect on their experiences. Fifth, it may have been valuable to have involved partners or grandparents in conducting interviews, to see if this generated unique insights based on shared perspectives. Inevitably researchers' own experiences (eg, of motherhood and perinatal mental health care) affect their interactions with participants and interpretations of the data: a male interviewer may, for example, have elicited different data from male partners, but all researchers were female. Finally, future research would benefit from exploring the perspectives of clinicians too, and placing greater emphasis on possible solutions to the challenges identified.

\section{Implications and conclusions}

Study findings suggest that engaging with wider interpersonal networks is challenging and complex, but too important to ignore. Perinatal mental health difficulties, and access to treatment, do not occur within a vacuum, but within a wider social and interpersonal context, in which the family plays an influential role. Our findings suggest a need for professionals to approach women's difficulties with greater focus on their social networks and to proactively challenge the ways in which the current set-up of services may reinforce dominant gender norms, and allow them to guide practice. At the same time, participants' ambivalence about family inclusion and the divergent needs and wishes expressed means there is a danger in making assumptions about what might be most helpful for them or how this might best work. Instead, at this stage research evidence is needed evaluating the effectiveness, acceptability and potential pitfalls of a range of potential approaches, preferably based on co-production principles to ensure the views of people with relevant lived experience and clinicians are central.

Possible approaches that merit further exploration include: (i) considering how to adapt current practice to make it more family-friendly (eg, by identifying acceptable ways to include partners/relatives more meaningfully in (at least some) appointments), (ii) challenging the way service structures currently deprioritise family members' needs, but also balancing this with protecting women's needs, (iii) developing or adapting couple or family-focused interventions for perinatal populations: previous reviews suggest that family therapy can help address and prevent perinatal depression, ${ }^{29} 30$ and that couple psychoeducation can support the transition to parenthood. ${ }^{31}$ In England, clinical guidelines recommend couple or family approaches for some perinatal mental health difficulties, ${ }^{14}$ but such interventions are rarely available and have not been extensively tested in the perinatal period ${ }^{22}$, (iv) developing and testing resources/interventions aimed at women's partners and wider families, acknowledging that some will themselves also have perinatal mental health needs: this will need to take into account that some family members express a preference for more 'informal' or 'incidental' forms of support (though this also may be partly a result of services treating them as ancillary) and (v) trialling specific staff training around engaging with families in the perinatal period, including awareness of cultural diversity.

At the same time, it is important to ensure that any changes to practice do not result in simply pathologising fathers as well as mothers, or holding families solely responsible for problems relating to perinatal distress and/or infant development. Rather, there is a need to look beyond the family as well, recognising that families too are operating within the constraints of their broader social contexts and the resources available to them. ${ }^{32}$ This 
may entail advocating for broader social changes to lessen the pressures on families.

Acknowledgements The authors are very grateful indeed for the advice and support received from the Perinatal Service User and Carer Advisory Group, and from the wider ESMI study team. The study team would also like to thank all the women and their family members who gave up their time to take part in the study.

Contributors BLT contributed to study concept and design, data collection, data analysis, interpretation of results and drafting of the manuscript. JB, NM, DB and SJ contributed to study concept and design and drafting of the manuscript. All authors read and approved the final manuscript.

Funding This paper summarises independent research funded by the National Institute for Health Research (NIHR) under its PGfAR Programme (Grant Reference Number RP-PG-1210-12002). The views expressed are those of the authors and not necessarily those of the NIHR or the Department of Health and Social Care. The study team acknowledges the study delivery support given by the local Clinical Research Networks. SJ is supported by the NIHR Mental Health Research Policy Unit, the NIHR Collaboration for Leadership in Applied Health Research and Care (CLAHRC) North Thames and the UCLH Biomedical Research Centre.

Competing interests None declared.

Ethics approval National Health Service ethics approval was obtained (reference:13/LO/1855).

Provenance and peer review Not commissioned; externally peer reviewed.

Data sharing statement The data sets generated and/or analysed during the current study are not publicly available due to them containing information that could compromise research participant privacy/consent but are available from the corresponding author on reasonable request.

Open access This is an open access article distributed in accordance with the Creative Commons Attribution Non Commercial (CC BY-NC 4.0) license, which permits others to distribute, remix, adapt, build upon this work non-commercially, and license their derivative works on different terms, provided the original work is properly cited, appropriate credit is given, any changes made indicated, and the use is non-commercial. See: http://creativecommons.org/licenses/by-nc/4.0/.

\section{REFERENCES}

1. Davey SJ, Dziurawiec S, O'Brien-Malone A. Men's voices: postnatal depression from the perspective of male partners. Qual Health Res 2006;16:206-20.

2. Engqvist I, Nilsson K. Men's experience of their partners' postpartum psychiatric disorders: narratives from the internet. Ment Health Fam Med 2011;8:137-46.

3. Muchena G. Men's experiences of partners' postnatal mental illness. Nurs Times 2007;103:32-3.

4. Boddy R, Gordon C, MacCallum F, et al. Men's experiences of having a partner who requires Mother and Baby Unit admission for first episode postpartum psychosis. J Adv Nurs 2017;73:399-409.

5. Blackmore ER, Rubinow DR, O'Connor TG, et al. Reproductive outcomes and risk of subsequent illness in women diagnosed with postpartum psychosis. Bipolar Disord 2013;15:394-404.

6. Paulson JF, Bazemore SD. Prenatal and postpartum depression in fathers and its association with maternal depression: a metaanalysis. JAMA 2010;303:1961-9.

7. Boath EH, Pryce AJ, Cox JL. Postnatal depression: The impact on the family. J Reprod Infant Psychol 1998;16(2-3):199-203.

8. Stein A, Pearson RM, Goodman SH, et al. Effects of perinatal mental disorders on the fetus and child. The Lancet 2014;384:1800-19.

9. Leahy-Warren P, McCarthy G, Corcoran P. First-time mothers: social support, maternal parental self-efficacy and postnatal depression. $J$ Clin Nurs 2012;21(3-4):388-97.
10. Grube M. Inpatient treatment of women with postpartum psychiatric disorders--the role of the male partners. Arch Womens Ment Health 2005;8:163-70.

11. Holopainen D. The experience of seeking help for postnatal depression. Aust J Adv Nurs 2002;19:39-44.

12. Letourneau N, Duffett-Leger L, Stewart M, et al. Canadian mothers' perceived support needs during postpartum depression. J Obstet Gynecol Neonatal Nurs 2007;36:441-9.

13. The Royal Australian and New Zealand College of Obstetricians and Gynaecologists (RANZCOG). Mental health care in the perinatal period. 2019 https://www.ranzcog.edu.au/RANZCOG SITE/media/ RANZCOG-MEDIA/Women\%27s\%20Health/Statement\%20and\% 20guidelines/Clinical-Obstetrics/Mental-health-care-in-the-perinatalperiod-(C-Obs-48).pdf?ext=.pdf (2019 Mar 3).

14. National Institute for Health and Clinical Excellence. Antenatal and postnatal mental health: clinical management and service guidance, Clinical Guideline CG192, 2014.

15. Lever Taylor B, Billings J, Morant N, et al. How do women's partners view perinatal mental health services? A qualitative meta-synthesis. Clin Psychol Psychother 2018;25:112-29.

16. Machin AJ. Mind the Gap: The expectation and reality of involved fatherhood. Father J Theory Res Men Parents 2015;13:36-59.

17. Baradon T. [Internet blog]. 'Out of mind': why do perinatal services not engage with fathers? https://www.annafreud.org/insights/blogs/ 2019/03/out-of-mind-why-do-perinatal-services-not-engage-withfathers/ (2019 Apr 7)

18. Hogg S. All Babies Count: spotlight on perinatal mental health prevention in mind. National Society for the Prevention of Cruelty to Children 2013.

19. Braun V, Clarke V. Using thematic analysis in psychology. Qual Res Psychol 2006;3:77-101.

20. NHS England. NHS long-term plan [Internet]. 2019 https://www. longtermplan.nhs.uk/wp-content/uploads/2019/01/nhs-long-termplan.pdf (2019 Jan 15).

21. WHO. WHO | Interventions for common perinatal mental disorders in women in low- and middle-income countries: a systematic review and meta-analysis [Internet]. https://www.who.int/bulletin/volumes/ 91/8/12-109819/en/ 2019 (2019 Apr 17).

22. Rosan C, Grimas E. The power of couple-focused approaches in the perinatal period. J Fam Health 2016;26:10-13.

23. Rose LE, Mallinson RK, Walton-Moss B. Barriers to family care in psychiatric settings. J Nurs Scholarsh 2004;36:39-47.

24. Wilkinson C, McAndrew S. 'I'm not an outsider, I'm his mother!' A phenomenological enquiry into carer experiences of exclusion from acute psychiatric settings. Int $J$ Ment Health Nurs 2008;17:392-401.

25. Allen K. Father experience of postpartum depression. Alliant International University 2010.

26. Letourneau N, Duffett-Leger L, Dennis CL, et al. Identifying the support needs of fathers affected by post-partum depression: a pilot study. J Psychiatr Ment Health Nurs 2011;18:41-7.

27. Addis ME, Mahalik JR. Men, masculinity, and the contexts of help seeking. Am Psychol 2003;58:5-14.

28. Filson B. The Haunting Can End: trauma-informed approaches in healing from abuse and adversity. Chapter 3 in Searching for a Rose Garden: Challenging Psychiatry, Fostering Mad Studies. Eds J Russo, A Sweeney 2016:pp 20-4.

29. Cluxton-Keller F, Bruce ML. Clinical effectiveness of family therapeutic interventions in the prevention and treatment of perinatal depression: A systematic review and meta-analysis. PLoS One 2018;13(6):e0198730.

30. Pinquart M, Teubert D. A Meta-analytic Study of Couple Interventions During the Transition to Parenthood. Fam Relat 2010;59:221-31.

31. Petch J, Halford WK. Psycho-education to enhance couples' transition to parenthood. Clin Psychol Rev 2008;28:1125-37.

32. Dallos R, Urry A. Abandoning our parents and grandparents: does social construction mean the end of systemic family therapy? J Fam Ther 1999;21:161-86. 